\title{
Differential Kidney Proteome Profiling in a Murine Model of Renal Fibrosis under Treatment with Mycophenolate Mofetil
}

\author{
Darinka T. Petrova $^{a}$ Franziska Brehmer ${ }^{a}$ Frank C. Schultze ${ }^{b}$ Abdul R. Asif $^{a}$ \\ Oliver Gross ${ }^{c}$ Michael Oellerich ${ }^{a}$ Gunnar Brandhorst ${ }^{a}$ \\ Departments of a Clinical Chemistry, ${ }^{\mathrm{b}}$ Gastroenterology and Endocrinology and ${ }^{\mathrm{C}}$ Nephrology and Rheumatology, \\ University Hospital Göttingen, Göttingen, Germany
}

\section{Key Words}

Mycophenolate mofetil $\cdot$ COL4A3-deficient mice $\cdot$

Tubulointerstitial fibrosis • Epithelial-mesenchymal

transition $\cdot$ Proteomics

\begin{abstract}
Aim: The aim of this study was to investigate the effect of mycophenolate mofetil (MMF) using differential kidney proteome profiling of COL4A3-deficient mice as a model of progressive renal disease. Methods: Histological evaluation of kidney sections was performed. Total protein lysate from kidneys of placebo- and MMF-treated COL4A3-deficient mice was studied for significant differences in protein abundance using 2-dimensional electrophoresis and mass spectrometry. Results: While tubulointerstitial fibrosis in COL4A3-deficient mice was inhibited by MMF, 19 proteins in the kidneys were regulated: 12 with lower (ATPO, TAGL2, CAH1, TPD52, VA0D1, SERPH, GNAL, PSB6, EF1D, OTUB1, NDUS8, and NAPSA) and 7 with higher (ACADM, ACY3, CK054, ACTB/G, ACTB, UBP5, and ACY1) spot intensity. Nine differentially expressed proteins showed interaction potential (ATPO, TPD52, PSB6, EF1D, OTUB1, NAPSA, ACTB, ACTG, and UBP5). Conclusions: The identified proteins take part in different
\end{abstract}

signaling pathways. With the highest probability, the VEGF signaling pathway (TAGL2, EF1D, and ACTB) and hypoxia (CAH1, PSB6, and ACTG) were influenced by MMF in fibrotic conditions. Moreover, MMF may modulate antifibrotic and apoptotic pathways as well as epithelial-mesenchymal transition (EMT). Different signaling pathways may be influenced by MMF therapy. These results suggest an inhibitory effect of MMF on renal EMT in COL4A3-deficient mice. Further studies are necessary to validate these findings.

Copyright $\odot 2011$ S. Karger AG, Basel

\section{Introduction}

The process of chronic renal diseases is typically accompanied by progressive renal fibrosis, and the inhibition of fibrogenesis appears to be an attractive therapeutic target. Recently, the antifibrotic role of mycophenolic acid (MPA) was shown in different studies [1-3]. Mycophenolate mofetil (MMF) as a prodrug of MPA is one of the most frequently used immunosuppressive drugs for the prophylaxis of allograft rejection after renal, cardiac, or liver transplant. It is known that MPA is a potent, selective, noncompetitive, and reversible inhibitor

Dr. Darinka T. Petrova

Department of Clinical Chemistry

University Hospital Göttingen

Robert-Koch-Strasse 40, DE-37075 Göttingen (Germany)

Tel. +4955139 13149, E-Mail darinka.petrova@med.uni-goettingen.de 
of inosine-5'-monophosphate dehydrogenase (IMPDH). Depleting guanosine and deoxyguanosine nucleotides inhibit the proliferation of $\mathrm{T}$ and $\mathrm{B}$ lymphocytes and, hence, immunoglobin production [4].

Epithelial-mesenchymal transition (EMT) is typical of embryonic cells (type 1), epithelial cells (type 2), or cells which are associated with cancer progression and metastasis (type 3) [5-9]. One recent study using renal proximal tubular epithelial cells demonstrated that MMF displays an inhibitory effect on EMT; moreover, it suggested less fibrosis and better long-term allograft survival under commonly used immunosuppressive regimens in renal transplantation [10]. Mechanisms for the inhibition of type 2 EMT upon MMF treatment, however, remain elusive.

COL4A3-deficient mice are a nonhypertensive animal model of progressive renal fibrosis. So far, this animal model has been used to study the pathobiology of human Alport syndrome. This syndrome is caused by mutations in type IV collagen genes (COL4), leading to an abnormal composition of the glomerular basement membrane and consequently to renal fibrosis [11]. In our recently published study, improved kidney function could be demonstrated for MMF-treated COL4A3-deficient mice [12]. In contrast to this observation, overall survival was not affected by MMF as compared to placebo treatment. To find an explanation for these contradictory findings, we designed a differential proteome profiling study using total protein extract from kidneys of MMF- and placebo-treated COL4A3-deficient mice following the hypothesis that MMF may influence type 2 EMT.

The main aim of this study was to identify differentially expressed proteins and their interacting partners in functional networks, as well as to predict signaling pathways involved in the pathological/therapeutic process within the context of MMF therapy in a murine model of renal fibrosis.

\section{Methods}

\section{COL4A3-Deficient Mice}

The COL4A3 gene locus is linked to an autosomal recessive form of human Alport syndrome. In this study COL4A3-deficient mice were used as a model of progressive renal disease (Jackson Laboratory, Bar Harbor, Me., USA). Animals were randomly allocated to a placebo or to 1 of 4 groups of MMF treatment (10, 50,100 , and $150 \mathrm{mg} / \mathrm{kg} /$ day). All animals received MMF or an equivalent amount of vehicle until somnolence was observed, as described previously [12].

Kidney Proteome of COL4A3-Deficient

Mice under MMF
Histological and Immunohistochemical Staining

Kidney paraffin-embedded sections were prepared from 1 representative mouse for each group as described previously for the assessment of glomerular damage [12]. Histological evaluation by light microscopy was performed after staining with hematoxylin and eosin. According to intertubular distance and tubular atrophy, tubulointerstitial fibrosis was scored semiquantitatively by 2 observers blinded to the groups. In accordance with Banff criteria [13] a score from 0 to $3+$ was assigned in 130 areas as follows: 0 , no tubulointerstitial changes; $1+,<25 \% ; 2+, 25-50 \%$, and $3+,>50 \%$.

For immunohistochemical staining, 5- $\mu \mathrm{m}$ paraffin-embedded sections were prepared for 1 representative placebo- and 1 MMF-treated animal (150 mg/kg/day). After the washing steps with phosphate buffered saline (PBS; PAA Laboratories $\mathrm{GmbH}$, Pasching, Austria) and blockage with bovine serum albumin (BSA; 5\% w/v in PBS) the sections were incubated overnight with primary antibody (rabbit anti-EHS-laminin, a gift from M. Paulsson, Cologne, Germany). Subsequently, the slides were incubated with the secondary antibody labeled with Cy3 fluorescent dye (goat anti-rabbit IgG; Jackson ImmunoReagents). A score from 0 to $3+$ was assigned in at least 350 areas independently by 2 observers blinded to the groups.

\section{Two-Dimensional Electrophoresis}

The kidneys from 5 placebo- and 5 MMF-treated mice (150 mg $\mathrm{MMF} / \mathrm{kg} /$ day) were snap frozen in liquid nitrogen immediately after preparation of the animal and stored at $-80^{\circ} \mathrm{C}$ until protein isolation. Halves from sagittal kidney sections were washed with cold PBS, and total protein was isolated from the samples by homogenization (Polytron ${ }^{\circledR}$ PT 3100; Kinematica AG, Kriens, Switzerland) and sonication (Branson Sonifier 250; Branson, USA) in $1 \mathrm{ml}$ total cell lysis buffer [7 mol/l urea, $2 \mathrm{~mol} / \mathrm{l}$ thiourea (SigmaAldrich Chemie GmbH, Steinheim, Germany), 4\% (w/v) CHAPS (AppliChem GmbH, Darmstadt, Germany), 2\% ampholytes (BioLyte $^{\circledR}$ 3/10; Bio-Rad, Munich, Germany), 1\% (w/v) DL-dithiothreitol, and $10 \mathrm{mmol} / \mathrm{l}$ phenylmethylsulfonyl fluoride (Sigma-Aldrich Chemie)]. Protein concentrations were determined according to the Bradford method [14] using a Bio-Rad protein assay kit (Bio-Rad) with BSA as the standard (2 $\mathrm{mg} / \mathrm{ml}$ Albumin Standard; Perbio Science Deutschland GmbH, Bonn, Germany).

Two-dimensional electrophoresis (2-DE) gels with each 125$\mu \mathrm{g}$ protein/immobilized $\mathrm{pH}$ gradient (IPG) strip were produced according to the protocol of Gorg et al. [15]. Briefly, 17-cm IPG strips with a nonlinear $\mathrm{pH}$ range of 3-10 (ReadyStrip ${ }^{\mathrm{TM}}$; Bio-Rad) were passively rehydrated with the samples and consequently the proteins were focused in a Protein IEF Cell (Bio-Rad). The strips were loaded onto a vertical $12.5 \%$ polyacrylamide gel for separation by molecular weight. After protein fixation and washing steps, the gels were stained according to the modified silver staining method of Blum et al. [16]. The silver-stained gels were scanned and the spot intensity evaluated as a percentage of the total intensity in the gel.

\section{Protein Identification}

The protein spots of interest were excised. Tryptic digestion and peptide sequence analysis by mass spectrometry were performed as published elsewhere [17]. Briefly, in-gel digestion was carried out according to a modified protocol of Shevchenko et al. [18]. After excision, the target protein spots were destained with 


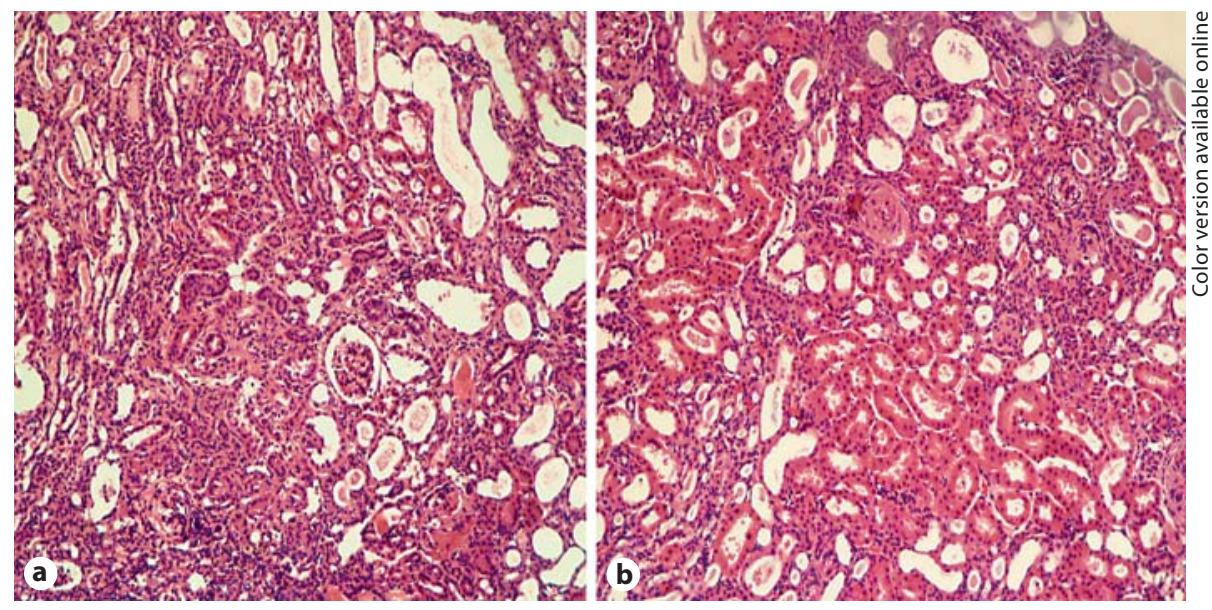

Fig. 1. Tubulointerstitial fibrosis in COL4A3-deficient mice was inhibited by MMF according to hematoxylin/eosin staining. Actual microphotograph of the histological findings of untreated $(0 \mathrm{mg}$ / $\mathrm{kg} /$ day; a) versus MMF-treated (150 mg/ $\mathrm{kg} /$ day; b) kidney. Magnification $\times 10$. c Score from 0 to $3+$ of the tubular compartment (0, no tubulointerstitial changes; $1+,<25 \% ; 2+, 25-50 \%$, and $3+,>50 \%)$ in 130 representative kidney areas of 1 placebo $(0 \mathrm{mg} / \mathrm{kg} /$ day $)$ and 1 mouse per group $(10,50,100$, and $150 \mathrm{mg} / \mathrm{kg} /$ day $)$.

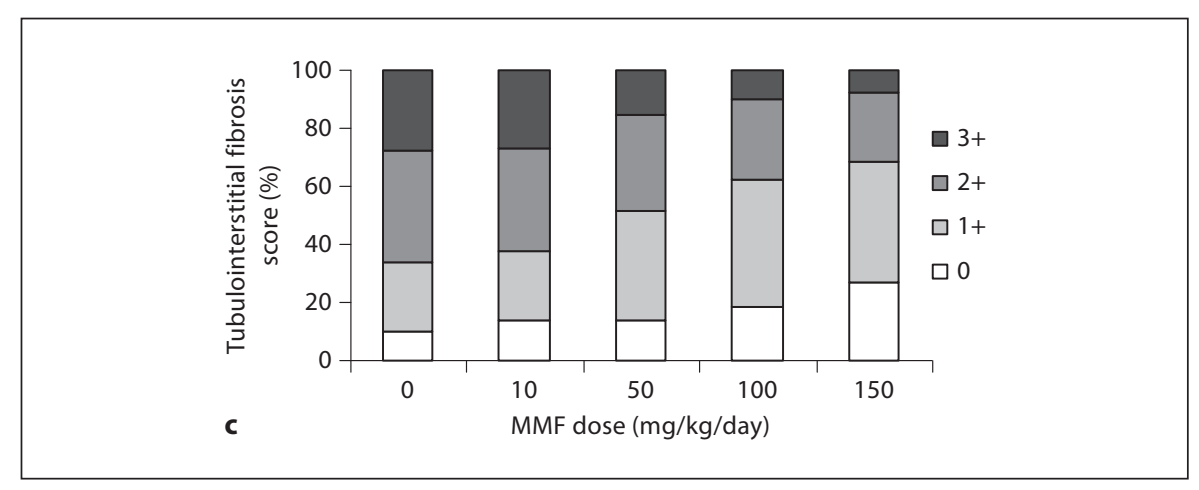

potassium ferricyanide and sodium thiosulphate (Merck KGaA, Darmstadt, Germany). The proteins/peptides were then digested with trypsin (Sigma-Aldrich Chemie). The gel slices were equilibrated with ammonium bicarbonate (Sigma-Aldrich Chemie) followed by incubation with acetonitrile (J.T. Baker, Deventer, The Netherlands). The peptides were extracted using triflouroacetic acid (Sigma-Aldrich Chemie) and acetonitrile. The solution with digested protein/peptide was dried in a speed vacuum system (UniEquip GmbH, Munich, Germany) and stored at $-20^{\circ} \mathrm{C}$ until further analysis. Every sample was diluted in $0.1 \%$ formic acid (BASF, Ludwigshafen, Germany), and $1 \mu \mathrm{l}$ was loaded for chromatographic separation on a CapLC-System (Waters, Milford, Mass., USA). Peptide sequence analysis was done on a Q-TOF Ultima Global mass spectrometer (Micromass, Manchester, UK) equipped with a nanoflow ESI Z-spray source in positive ion mode. Obtained data were processed and searched against MSDB and Swiss-Prot data bases through the Mascot search engine with oxidation $(\mathrm{M})$ and carbamidomethyl $(\mathrm{C})$ modification.

\section{Software and Statistics}

The densitometric quantification of spot intensity was done using the Delta2D software tool, version 3.4, 2006 (DECODON GmbH, Greifswald, Germany) [19]. A Mann-Whitney U test was performed using PASW Statistics 18 software for statistical evaluation (SPSS, Inc., Chicago, Ill., USA) to evaluate the differences in protein amount between the groups. $\mathrm{p}<0.05$ was considered sta- tistically significant. The data obtained from mass spectrometry were processed using MassLynx, version 4.0 (Micromass). The Molecular INTeraction database (MINT; http://mint.bio.uniro$\mathrm{ma2.it/mint/Welcome.do)} \mathrm{was} \mathrm{used} \mathrm{to} \mathrm{analyze} \mathrm{protein} \mathrm{relation-}$ ships and to predict functional networks [20].

\section{Results}

\section{Tubulointerstitial Fibrosis}

Observers, blinded to the treatment groups of COL4A3-deficient mice, examined tubular atrophy and intertubular distance after staining with hematoxylin and eosin and assigned a score from 0 to $3+$ (fig. 1c). Tubulointerstitial fibrosis was inhibited by MMF.

The immunohistochemical staining of EHS-laminin is directed mainly to laminin 1 in the extracellular matrix. The evaluation of tubulointerstitial fibrosis confirmed inhibition by MMF in treated COL4A3-deficient mice (fig. 2c). All sections also showed intra- and periglomerular laminin deposition indicative of the expected glomerular damage. 

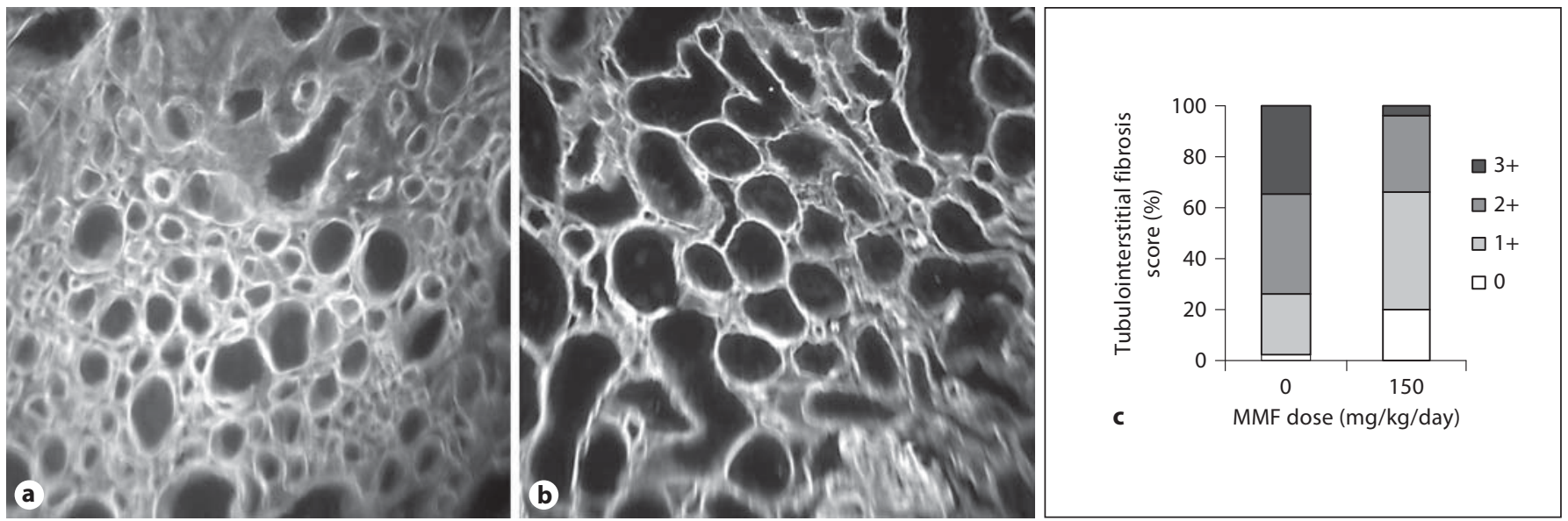

Fig. 2. Tubulointerstitial fibrosis in COL4A3-deficient mice was inhibited by MMF according to immunostaining of EHS-laminin. Actual microphotograph of the histological findings of untreated (0 mg/kg/day; a) versus MMF-treated ( $150 \mathrm{mg} / \mathrm{kg} /$ day; b)

kidney. Magnification $\times 40$. c Score from 0 to $3+(0$, no tubulointerstitial changes; $1+,<25 \% ; 2+, 25-50 \%$, and $3+,>50 \%)$ in 350 representative kidney areas of 1 placebo- $(0 \mathrm{mg} / \mathrm{kg} /$ day $)$ and 1 MMF-treated mouse (150 mg/kg/day).

\section{Two-Dimensional Electrophoresis}

Ten images of silver-stained 2-DE gels were evaluated with the software Delta2D, and spots of interest were subjected to in-gel digestion and mass spectrometry (fig. 3). The analysis revealed 17 proteins with significant changes in relative intensity ( $p<0.05$, Mann-Whitney $U$ test; fig. 4) between placebo- and MMF-treated mice (150 $\mathrm{mg} / \mathrm{kg} /$ day), while differences for 2 protein spots narrowly missed significance. All 19 proteins were successfully identified by mass spectrometry with more than 2 peptides (online supplementary table S1, www. karger.com/doi/10.1159/000324597).

Twelve proteins out of 19 spots displayed significantly less intense staining after treatment with MMF of COL4A3-deficient mice: ATP synthase subunit $\mathrm{O}$, mitochondrial (ATPO), transgelin-2 (TAGL2), carbonic anhydrase 1 (CAH1), tumor protein D52 (TPD52), V-type proton ATPase subunit d 1 (VA0D1), serpin H1 (SERPH), guanine nucleotide-binding protein $\mathrm{G}(\mathrm{olf})$ subunit alpha (GNAL), proteasome subunit beta type 6 (PSB6), elongation factor 1-delta (EF1D), ubiquitin thioesterase OTUB1 (OTUB1), NADH dehydrogenase (ubiquinone) iron-sulfur protein 8, mitochondrial (NDUS8), and napsin-A (NAPSA).

The spot intensity of 7 proteins was higher after MMF treatment; these included medium-chain specific acylCoA dehydrogenase, mitochondrial (ACADM), aspartoacylase-2 (ACY3), ester hydrolase C11orf54 homolog (CK054), actin, cytoplasmic 1 and/or actin, cytoplasmic

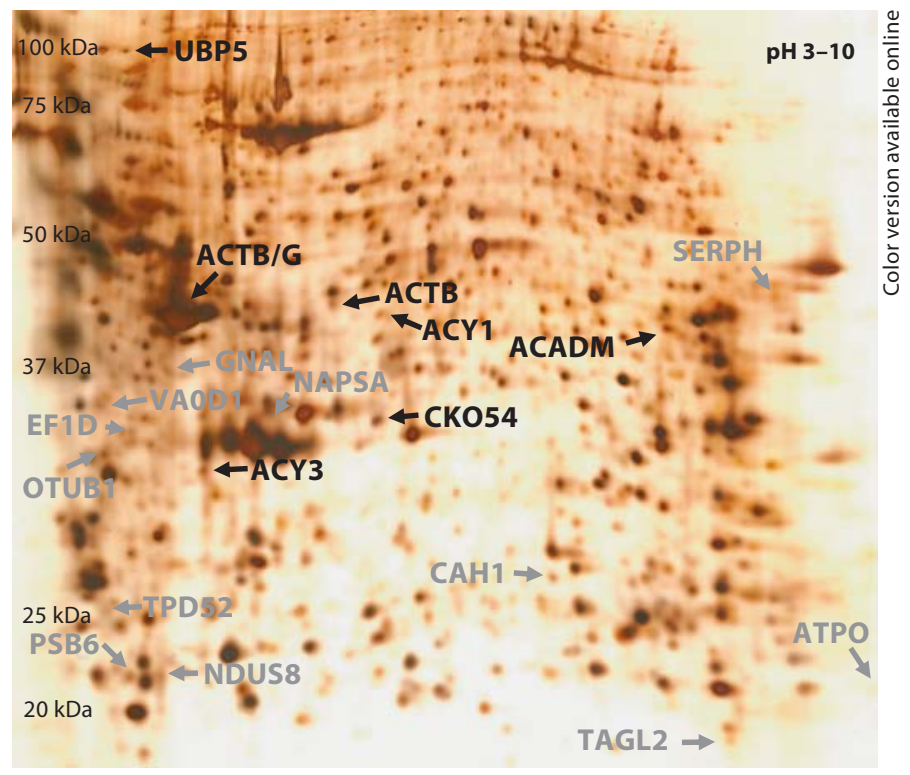

Fig. 3. Representative area of a 2-dimensional gel after silverstaining using total protein extract from the kidney of a COL4A3deficient mouse. Protein spots with a difference upon MMF treatment are in black if upregulated and in grey if downregulated.

$2(\mathrm{ACTB} / \mathrm{G})$, actin, cytoplasmic 1 (ACTB), ubiquitin carboxyl-terminal hydrolase 5 (UBP5), and aminoacylase-1 (ACY1). As indicated above, the differences for ACY1 and ACTB/G were not significant according to the MannWhitney $U$ test. An over 2-fold change in spot intensity 


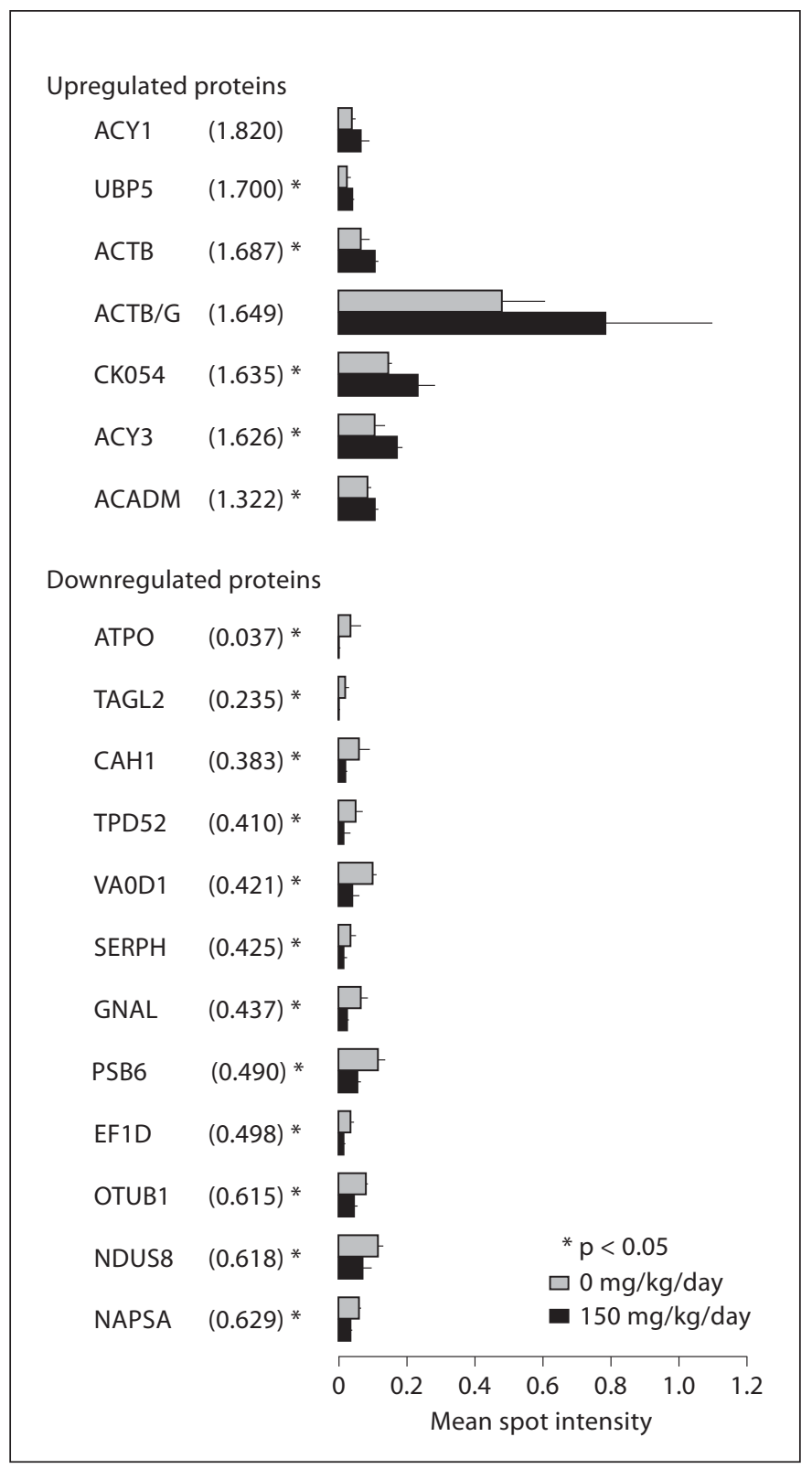

Fig. 4. Spot intensity in kidney total protein extract from COL4A3-deficient mice treated with MMF ( $\mathrm{n}=5$; black bars) compared to the placebo group ( $n=5$; grey bars). Proteins with significant differences in protein amount are asterisked $(\mathrm{p}<0.05$, Mann-Whitney $U$ test). The mean ratio of $\mathrm{MMF} /$ placebo mice is given parentheses.

was shown in $75 \%$ of the downregulated proteins under MMF treatment (PSB6, VA0D1, GNAL, CAH1, TPD52, EF1D, SERPH, TAGL2, and ATPO) (fig. 4). Overall, the proteins showed good agreement between the observed and calculated values regarding molecular weight as well as their isoelectric point (table 1).

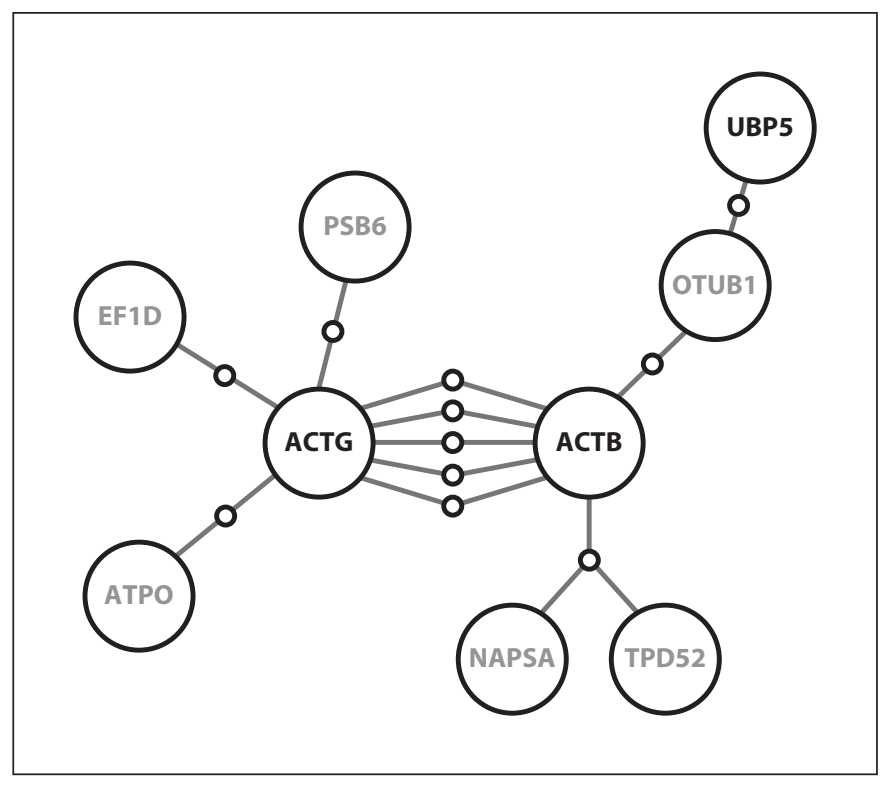

Fig. 5. Network of interacting proteins using the MINT database. Proteins with a higher or lower concentration in MMF-treated COL4A3-deficient mice are in black or grey, respectively. The small circles are proteins which connect the proteins we have identified in our study. The lines illustrate the links between all of the proteins in one network.

In order to find the interconnectivity of the proteins, we performed a data analysis using the MINT software tool and found, as expected, 9 out of 19 proteins to be predicted interacting partners: ATPO, TPD52, PSB6, EF1D, OTUB1, NAPSA, ACTB, ACTG, and UBP5 (fig. 5).

\section{Discussion}

We investigated the effect of MMF on histological, immunohistological, and proteome levels in kidneys from COL4A3-deficient mice as a model of progressive renal disease. Since sections from COL4A3-deficient mice treated with MMF revealed an attenuated peritubular and particularly interstitial deposition of EHS-laminin, and tubulointerstitial fibrosis was inhibited upon MMF (fig. 1,2), we suggested that this may be indicative of a preserved nephron function. This is in line with a study showing reduced interstitial fibrosis and ameliorated EMT in a rat model of adenine-induced chronic renal failure [21]. Presuming that MMF influences EMT, we undertook differential proteome profiling using total protein extract from the kidneys of MMF- and placebotreated COL4A3-deficient mice. 
Table 1. Isoelectric point, molecular weight, and function of regulated proteins in kidney proteome of COL4A3-deficient mice after MMF treatment

\begin{tabular}{|c|c|c|c|c|}
\hline Protein name & $\begin{array}{l}\text { Spot } \\
\text { label }\end{array}$ & $\begin{array}{l}\text { pI } \\
\text { obs./calc. }\end{array}$ & $\begin{array}{l}\text { MW (kDa) } \\
\text { obs./calc. }\end{array}$ & Function \\
\hline \multicolumn{5}{|c|}{$>25 \%$ downregulated proteins under MMF } \\
\hline $\begin{array}{l}\text { ATP synthase subunit } \mathrm{O} \text {, } \\
\text { mitochondrial }\end{array}$ & ATPO & $9.75 / 10.0$ & $24 / 23.349$ & Mitochondrial membrane ATP synthase \\
\hline Transgelin-2 & TAGL2 & $8.5 / 8.39$ & $20 / 22.381$ & $\begin{array}{l}\text { Homolog of the protein transgelin, one of the } \\
\text { earliest markers of differentiated smooth } \\
\text { muscle }\end{array}$ \\
\hline Carbonic anhydrase 1 & CAH1 & $7.0 / 6.44$ & $26 / 28.303$ & $\begin{array}{l}\text { Metalloenzyme catalyzing the rapid conversion } \\
\text { of carbon dioxide to bicarbonate and protons }\end{array}$ \\
\hline Tumor protein D52 & TPD52 & $3.5 / 4.69$ & $25 / 24.298$ & $\begin{array}{l}\text { Regulator of membrane trafficking events } \\
\text { within exocytic pathways }\end{array}$ \\
\hline V-type proton ATPase subunit d 1 & VA0D1 & $3.5 / 4.89$ & $36 / 40.275$ & $\begin{array}{l}\text { Component of vacuolar ATPase mediating } \\
\text { acidification necessary for intracellular } \\
\text { processes }\end{array}$ \\
\hline Serpin H1 & SERPH & $9.0 / 8.9$ & $45 / 46.560$ & $\begin{array}{l}\text { Cell proliferation-inducing and } \\
\text { collagen-binding heat shock protein }\end{array}$ \\
\hline $\begin{array}{l}\text { Guanine nucleotide-binding protein } \\
\text { G(olf) subunit alpha }\end{array}$ & GNAL & $4.25 / 6.23$ & $40 / 44.280$ & $\begin{array}{l}\text { Modulator/transducer in transmembrane } \\
\text { signaling systems }\end{array}$ \\
\hline Proteasome subunit beta type- 6 & PSB6 & $4.0 / 4.97$ & $24 / 25.362$ & $\begin{array}{l}\text { Subunit of a multicatalytic proteinase complex } \\
\text { cleaving peptide bonds with very broad } \\
\text { specificity }\end{array}$ \\
\hline Elongation factor 1-delta & EF1D & $4.0 / 4.91$ & $30 / 31.274$ & $\begin{array}{l}\text { Subunit of complex responsible for the } \\
\text { enzymatic delivery of aminoacyl tRNAs to } \\
\text { the ribosome }\end{array}$ \\
\hline Ubiquitin thioesterase OTUB1 & OTUB1 & $3.5 / 4.85$ & $30 / 31.250$ & $\begin{array}{l}\text { High specific ubiquitin isopeptidase cleaving } \\
\text { ubiquitin from branched polyubiquitin chains }\end{array}$ \\
\hline $\begin{array}{l}\text { NADH dehydrogenase } \\
\text { (ubiquinone) iron-sulfur } \\
\text { protein 8, mitochondrial } \\
\end{array}$ & NDUS8 & $4.25 / 5.86$ & $24 / 24.023$ & $\begin{array}{l}\text { Mitochondrial membrane enzyme catalyzing } \\
\text { the transfer of electrons from NADH to } \\
\text { coenzyme Q }\end{array}$ \\
\hline Napsin-A & NAPSA & $5.0 / 7.14$ & $36 / 45.516$ & $\begin{array}{l}\text { Aspartic proteinase from the endopeptidase } \\
\text { class }\end{array}$ \\
\hline \multicolumn{5}{|c|}{$>25 \%$ upregulated proteins under MMF } \\
\hline $\begin{array}{l}\text { Medium-chain specific } \\
\text { acyl-CoA dehydrogenase, } \\
\text { mitochondrial }\end{array}$ & ACADM & $8.0 / 8.6$ & $42 / 46.452$ & $\begin{array}{l}\text { Flavoenzyme involved in fatty acid and } \\
\text { branched-chain amino acid metabolism }\end{array}$ \\
\hline Aspartoacylase-2 & ACY3 & $4.5 / 5.3$ & $30 / 35.264$ & $\begin{array}{l}\text { Protein important in deacetylating } \\
\text { mercapturic acids in kidney proximal tubules }\end{array}$ \\
\hline $\begin{array}{l}\text { Ester hydrolase C11orf54 } \\
\text { homolog }\end{array}$ & CK054 & $5.75 / 5.86$ & $35 / 34.973$ & $\begin{array}{l}\text { Zinc ion binding hydrolase acting on ester } \\
\text { bonds in the nucleus }\end{array}$ \\
\hline $\begin{array}{l}\text { Actin, cytoplasmic } 1 \text { and/or } \\
\text { actin, cytoplasmic } 2\end{array}$ & $\begin{array}{l}\text { ACTB and/ } \\
\text { or ACTG }\end{array}$ & $\begin{array}{l}4.5 / 5.29 \text { and/ } \\
\text { or } 5.31\end{array}$ & $\begin{array}{l}42 / 41.710 \text { and/ } \\
\text { or } 41.766\end{array}$ & $\begin{array}{l}\text { Conserved proteins of the contractile } \\
\text { apparatus and cytoskeleton, mediators of } \\
\text { internal cell motility }\end{array}$ \\
\hline Actin, cytoplasmic 1 & ACTB & $5.5 / 5.29$ & $42 / 41.710$ & See above \\
\hline $\begin{array}{l}\text { Ubiquitin carboxyl-terminal } \\
\text { hydrolase } 5\end{array}$ & UBP5 & $4.0 / 4.89$ & $100 / 95.772$ & $\begin{array}{l}\text { Protein involved in the processing of } \\
\text { polyubiquitin precursors and ubiquinated } \\
\text { proteins }\end{array}$ \\
\hline Aminoacylase-1 & ACY1 & $5.75 / 5.89$ & $42 / 45.752$ & $\begin{array}{l}\text { Zinc ion binding peptidase in amino acid } \\
\text { metabolic process/proteolysis }\end{array}$ \\
\hline
\end{tabular}

pI = Isoelectric point; obs. = observed; calc. = calculated. 
The protein profile was obtained from whole kidney extracts and supported robust changes in tubular cells, mesangial cells, and glomerular structures, among others. Since approximately $90 \%$ of the kidney's volume is tubulointerstitial space [22] and only the fibrosis in the tubulointerstitial (fig. 1), and not in the glomerular [12], compartment was inhibited by MMF, the regulated proteins reflected changes predominantly in that space. To find the interconnectivity of the proteins, we performed a data analysis using the MINT software tool and found ATPO, TPD52, PSB6, EF1D, OTUB1, NAPSA, ACTB, ACTG, and UBP5 to be predicted interacting partners (fig. 5). Since this database is broader for human data, we provided accession numbers for human proteins, respectively, to analyze the relationship between the identified proteins using the MINT database. However, it should be noted that expression and regulation of these proteins can be very different between mice and humans in a normal or disease state.

The identified proteins take part in different signaling pathways supporting a complex picture of EMT events modulated through small GTPases, p53, phosphoinositide 3-kinases (PI3Ks), mitogen-activated protein kinases (MAPKs), and other molecules presented by Kalluri and Neilson [5], as well as cross talk between the 3 distinct EMT types. Some of the proteins from our set are involved in the vascular endothelial growth factor (VEGF) signaling pathway (TAGL2, EF1D, and ACTB) and in hypoxia (CAH1, PSB6, and ACTG); this seems to be in accordance with the literature since the collagenous matrix of fibrogenesis inhibits vascular supply and the perimeter of viability for fibroblasts regresses to the point where scars become acellular [22], and hypoxia as environmental stress was thought to be one of the factors in the peritubular microenvironment that induce/promote EMT [9].

TAGL2 shows GTPase activity. This protein is significantly downregulated in the current experimental model. It crosses the p53 pathway and is related to apoptosis together with ATPO, TPD52, and OTUB, which are also downregulated upon MMF therapy and thereby possibly reflect a reduced proapoptotic effect. It was reported that TPD52 expression, either in human or in mouse fibroblasts, correlates with the acquisition of epithelial characteristics by these cells [23]. Given that TPD52 is expressed at higher levels by kidney epithelial cells [23] and that EMT generates cells with properties of stem cells [24], it was not surprising that we found 2 proteins relevant to stem cells, i.e. SERPH and UBP5. In the current mouse model for renal fibrosis these proteins probably influenced different cellular events during the cell cycle, cell proliferation, differentiation, motility, self-renewing, or migration. The heat shock protein SERPH is supposed to interact with different proteins, including TGF- $\beta$, and thus induces cell proliferation. SERPH binds to collagen fibrils and could be involved as a chaperone in the biosynthetic pathway of collagen. In the present in vivo study this protein was present in a significantly lower amount upon MMF. This could explain the significant inhibition of cell proliferation, contractile activity, and wound closure upon MPA treatment of fibroblast cell line COS-7 in our previous in vitro study [3].

The MAPK signaling pathway appears to be involved in tubulointerstitial fibrosis in COL4A3-deficient mice since EF1D and ACTG join this pathway, and the PI3K/ AKT signaling pathway also might be involved when discussing the EF1D interactions. This is in line with recent reviews describing that Ras-MAPK and PI3K/AKT signaling pathways, as well as type I collagen, induce EMT $[7,9,25]$.

It was suggested that modulation of epithelial cell plasticity has therapeutic advantages since it offers a novel therapeutic target to potentially inhibit renal fibrogenesis [6]. Interestingly, it was shown that the immunosuppressive drug MMF displays an inhibitory effect on EMT, suggesting less renal fibrosis [10]. Herein, we confirmed an antifibrotic effect of MMF in vivo and revealed proteome changes under fibrotic conditions. Considering all proteins from our screening relating to EMT, we concluded that there were 7 proteins with a potential association to EMT, i.e. 2 upregulated (ACTG and UBP5) and 5 downregulated proteins (CAH1, PSB6, TPD52, SERPH, and EF1D). Moreover, 5 of these 7 proteins belong to the network of predicted interacting proteins using the MINT database (ACTG, UBP5, PSB6, TPD52, and EF1D) (fig. 5).

ATPO is downregulated upon MMF treatment. ATPO constitutes a subunit of the ATP synthase producing ATP in the presence of a proton gradient across the mitochondrial membrane. ATP and GTP are used for short-term energy storage and for synthesis of DNA and RNA. These molecules are synthesized de novo by interconversion, salvage, or catabolism. These pathways are well regulated and are of major clinical interest since through them nucleotide analog antiviral and antitumor drugs were taken up, activated, and catabolized. Guanine nucleotide-binding proteins ( $\mathrm{G}$ proteins) are involved as modulators, or transducers, in various transmembrane signaling systems. GNAL is a G protein which is associated with inflammatory responses and autoimmunity. GNAL is sig- 
nificantly less expressed in kidneys from treated mice, just like the EF1D subunit acting as the guanine nucleotide exchange factor (GEF). It is known that MPA inhibits DNA synthesis through reduction of the intracellular GTP pool by blocking the IMPDH pathway as IMPDH plays the role of a key enzyme in de novo purine nucleotide biosynthesis. MPA-induced GTP depletion also affects ATP synthesis in human T lymphocytes [26] as we observed indirectly in the current kidney study with COL4A3-deficient mice through downregulation of ATPO.

In kidney but also in liver and intestinal microsomes MPA undergoes glucuronidation to the active metabolite AcMPAG [27]. Kidneys have been shown to be particularly efficient in the excretion of over $90 \%$ of MPA exclusively as glucuronide metabolites [28]. Interestingly, 3 proteins, i.e. ACTB, CKO54, and ACY1, were significantly upregulated in the current profiling of COL4A3-deficient mice upon MMF and they were shown to form putative adducts with AcMPAG in kidneys of Wistar rats treated with $40 \mathrm{mg} \mathrm{MMF} / \mathrm{kg} /$ day [17]. It is thought that adducts contribute to drug toxicity through changes in the functional properties of the molecules or through an- tigen formation followed by immune reactions. Both actins, i.e. ACTB and ACTG, are nucleotide-binding components of the cytoskeleton and at the same time mediators of internal cell motility. They were upregulated upon MMF like the Zn-binding hydrolase CKO54 and both Zn-binding aminoacylases. Aminoacylases ACY1 and ACY3 are involved in the hydrolysis of $\mathrm{N}$-acylated or $\mathrm{N}$ acetylated amino acids (except $\mathrm{L}$-aspartate) and in deacetylating mercapturic acids in kidney proximal tubules, respectively.

In conclusion, we provide descriptive data on proteome changes after MMF treatment of an in vivo model of progressive renal disease with inhibited tubulointerstitial fibrosis indicative of an inhibitory effect of MMF on renal EMT. Further studies are necessary to validate and extend these findings with continuous data over time.

\section{Acknowledgement}

This study was partially supported by Roche Pharma AG, Grenzach-Wyhlen, Germany.

\section{References}

1 Waller JR, Brook NR, Bicknell GR, Murphy GJ, Nicholson ML: Mycophenolate mofetil inhibits intimal hyperplasia and attenuates the expression of genes favouring smooth muscle cell proliferation and migration. Transplant Proc 2005;37:164-166.

$\checkmark 2$ Roos N, Poulalhon N, Farge D, Madelaine I, Mauviel A, Verrecchia F: In vitro evidence for a direct antifibrotic role of the immunosuppressive drug mycophenolate mofetil. J Pharmacol Exp Ther 2007;321:583-589.

$\checkmark 3$ Petrova DT, Brandhorst G, Brehmer F, Gross O, Oellerich M, Armstrong VW: Mycophenolic acid displays IMPDH-dependent and IMPDH-independent effects on renal fibroblast proliferation and function. Ther Drug Monit 2010;32:412-412.

4 Villarroel MC, Hidalgo M, Jimeno A: Mycophenolate mofetil: an update. Drugs Today (Barc) 2009;45:521-532.

$\checkmark 5$ Kalluri R, Neilson EG: Epithelial-mesenchymal transition and its implications for fibrosis. J Clin Invest 2003;112:1776-1784.

6 Zeisberg M, Kalluri R: The role of epithelialto-mesenchymal transition in renal fibrosis. J Mol Med 2004;82:175-181.

7 Willis BC, Borok Z: TGF-beta-induced EMT: mechanisms and implications for fibrotic lung disease. Am J Physiol Lung Cell Mol Physiol 2007;293:L525-L534.
8 Kalluri R, Weinberg RA: The basics of epithelial-mesenchymal transition. J Clin Invest 2009;119:1420-1428.

$\checkmark 9$ Liu Y: New insights into epithelial-mesenchymal transition in kidney fibrosis. J Am Soc Nephrol 2010;21:212-222.

10 Copeland JW, Beaumont BW, Merrilees MJ, Pilmore HL: Epithelial-to-mesenchymal transition of human proximal tubular epithelial cells: effects of rapamycin, mycophenolate, cyclosporin, azathioprine, and methylprednisolone. Transplantation 2007;83: 809-814.

11 Gross O, Koepke ML, Beirowski B, SchulzeLohoff E, Segerer S, Weber M: Nephroprotection by antifibrotic and anti-inflammatory effects of the vasopeptidase inhibitor AVE7688. Kidney Int 2005;68:456-463.

12 Brandhorst G, Brehmer F, Petrova DT, Gross O, Miosge N, Armstrong VW, Oellerich M: Mycophenolic acid predose concentrations and renal function in a mouse model for progressive renal fibrosis. Ther Drug Monit 2010;32:73-78.
13 Racusen LC, Solez K, Colvin RB, Bonsib SM, Castro MC, Cavallo T, Croker BP, Demetris AJ, Drachenberg CB, Fogo AB, Furness $P$, Gaber LW, Gibson IW, Glotz D, Goldberg JC, Grande J, Halloran PF, Hansen HE, Hartley B, Hayry PJ, Hill CM, Hoffman EO, Hunsicker LG, Lindblad AS, Yamaguchi Y, et al: The Banff 97 working classification of renal allograft pathology. Kidney Int 1999;55:713723 .

14 Bradford MM: A rapid and sensitive method for the quantitation of microgram quantities of protein using the principle of protein-dye binding. Anal Biochem 1976;72:248-254.

$>15$ Gorg A, Obermaier C, Boguth G, Harder A, Scheibe B, Wildgruber R, Weiss W: The current state of two-dimensional electrophoresis with immobilized $\mathrm{pH}$ gradients. Electrophoresis 2000;21:1037-1053.

$>16$ Blum H, Beier H, Gross HJ: Improved silver staining of plant proteins, RNA and DNA in polyacrylamide gels. Electrophoresis 1987;8: 93-99.

-17 Asif AR, Armstrong VW, Voland A, Wieland E, Oellerich M, Shipkova M: Proteins identified as targets of the acyl glucuronide metabolite of mycophenolic acid in kidney tissue from mycophenolate mofetil treated rats. Biochimie 2007;89:393-402. 
-18 Shevchenko A, Wilm M, Vorm O, Mann M: Mass spectrometric sequencing of proteins from silver-stained polyacrylamide gels. Anal Chem 1996;68:850-858.

19 Luhn S, Berth M, Hecker M, Bernhardt J: Using standard positions and image fusion to create proteome maps from collections of two-dimensional gel electrophoresis images. Proteomics 2003;3:1117-1127.

-20 Chatr-aryamontri A, Ceol A, Palazzi LM, Nardelli G, Schneider MV, Castagnoli L, Cesareni G: MINT: the Molecular INTeraction database. Nucleic Acids Res 2007;35:D572D574.

-21 He CM, Zheng FL, Liu YP: The effects of mycophenolate mofetil on renal interstitial fibrosis and epithelial-myofibroblast translation in adenine-induced renal failure rats. Zhonghua Nei Ke Za Zhi 2008;47:901-905.
22 Strutz F, Neilson EG: New insights into mechanisms of fibrosis in immune renal injury. Springer Semin Immunopathol 2003; 24:459-476.

23 Byrne JA: Tumor protein D52. UCSD-Nature Signaling Gateway Molecule Pages 2006, DOI: 10.1038/mp.a000072.01.

24 Mani SA, Guo W, Liao MJ, Eaton EN, Ayyanan A, Zhou AY, Brooks M, Reinhard F, Zhang CC, Shipitsin M, Campbell LL, Polyak K, Brisken C, Yang J, Weinberg RA: The epithelial-mesenchymal transition generates cells with properties of stem cells. Cell 2008; 133:704-715.

25 Chung L: Prostate Cancer: Biology, Genetics and the New Therapeutics. New Jersey, Humana Press, 2007.
26 Qiu Y, Fairbanks LD, Rückermann K, Hawrlowicz CM, Richards DF, Kirschbaum B, Simmonds HA: Mycophenolic acid-induced GTP depletion also affects ATP and pyrimidine synthesis in mitogen-stimulated primary human T-lymphocytes. Transplantation 2000;69:890-897.

27 Shipkova M, Strassburg CP, Braun F, Streit F, Gröne HJ, Armstrong VW, Tukey RH, Oellerich M, Wieland E: Glucuronide and glucoside conjugation of mycophenolic acid by human liver, kidney and intestinal microsomes. Br J Pharmacol 2001;132:1027-1034.

28 Bullingham RE, Nicholls AJ, Kamm BR: Clinical pharmacokinetics of mycophenolate mofetil. Clin Pharmacokinet 1998;34: 429-455. 